\title{
Dose of remifentanil for minimizing the cardiovascular changes to tracheal intubation in pediatric patients
}

\author{
Sang-Ho Yoon, Kyung-Han Kim, and Suk-Hwan Seo \\ Department of Anesthesiology and Pain Medicine, Kosin University College of Medicine, Busan, Korea
}

Background: The purpose of this study was to investigate a dosage of remifentanil for attenuating cardiovascular changes during anesthetic induction in pediatric anesthesia.

Methods: We examined the effect of remifentanil on the cardiovascular responses to intubation in 90 children ASA 1 patients, aged 4-15 years, randomly allocated to receive $1.0 \mathrm{ug} / \mathrm{kg}$ remifentanil as a bolus (R 1), or $1.5 \mathrm{ug} /$ $\mathrm{kg}$ remifentanil (R 1.5), or $2.0 \mathrm{ug} / \mathrm{kg}$ remifentanil (R 2). Before induction, IV midazolam $0.05 \mathrm{mg} / \mathrm{kg}$ was given for sedation. After glycoppylorate $5 \mathrm{ug} / \mathrm{kg}$, thiopental $4.0 \mathrm{mg} / \mathrm{kg}$ was injected within 10 seconds and followed by remifentanil. Following check the unconsciousness, patients were received rocuronium $0.6 \mathrm{mg} / \mathrm{kg}$ and tracheal intubation were performed 90 s later, and anesthesia was maintained with $2 \%$ sevoflurane in air/oxygen. Systolic arterial pressure (SAP), mean arterial pressure (MAP) and heart rate (HR) were measured at before induction of anesthesia (B), before, just after and at 1 , and 3 minutes after tracheal intubation.

Results: SAP and HR were increased than $\mathrm{B}$ values in the three groups just after intubation $(\mathrm{P}<0.05)$. The percentage increases of SAP and HR were $30 \%$ and $30 \%$ of B values, respectively, in R 1; $19 \%$ and $24 \%$ in R $1.5 ; 10 \%$ and $22 \%$ in R 2 . There were significant differences between R 2 group and other two groups in SAP and $\mathrm{HR}(\mathrm{P}<0.05)$.

Conclusions: In pediatric anesthesia, a bolus injection of $2 \mathrm{ug} / \mathrm{kg}$ remifentanil (R 2) was a dosage to attenuate the cardiovascular responses after intubation in pediatric patients. (Korean J Anesthesiol 2010; 59: 167-172)

Key Words: Cardiovascular changes, Children, Remifentanil, Tracheal intubation.

Received: April 16, 2010. Revised: 1st, May 3, 2010; 2nd, May 24, 2010. Accepted: June 3, 2010.

Corresponding author: Kyung-Han Kim, M.D., Department of Anesthesiology and Pain Medicine, Kosin University College of Medicine, Amnam-dong, Seo-gu, Busan 602-702, Korea. Tel: 82-51-990-6283, Fax: 82-51-254-2504, E-mail: kimkh@kosinmed.or.kr

The 86th Annual Scientific Meeting of Korean Society of Anesthesiologists, 2009, Jeju, Korea.

(c) This is an open-access article distributed under the terms of the Creative Commons Attribution Non-Commercial License (http:// creativecommons.org/licenses/by-nc/3.0/), which permits unrestricted non-commercial use, distribution, and reproduction in any medium, provided the original work is properly cited. 


\section{Introduction}

When performing adult general anesthesia, endotracheal intubation (ETI) using a laryngoscope stimulates the sympathetic nervous system and it raises the blood pressure, the heart rate and the, catecholamine concentration in the blood $[1,2]$. Raising the blood pressure and heart rate increases the danger of myocardial ischemia, left ventricular failure, arrhythmia, and cerebral hemorrhage [3-5]. Likewise in pediatric anesthesia, endotracheal intubation using a laryngoscope temporarily raises the catecholamine concentration and greatly increases the systolic blood pressure and heart rate [6]. Such temporary increases in the cardiovascular responses in the patients with pulmonary hypertension, and cerebral vascular malformation, and the increased intracranial pressure poses a potential threat; therefore it is important to prevent the cardiovascular changes due to ETI $[7,8]$. The use of opioids can decrease such cardiovascular responses [9-11]. Compared with the currently marketed fentanyl congeners, the pharmacokinetic profile of remifentanil is unique. Remifentanil has an ester-bond and this is quickly hydrolyzed by nonspecific esterase in the plasma and the organs. Its maximum effect kicks in within $30-90 \mathrm{sec}$; its context-sensitive half life is less than 5 minutes. So regardless of the infusion time, when the remifentanil infusion is stopped, its effect quickly ceases and the emergence from remifentanil becomes predictable [12]. Therefore, opioids of an appropriate dose are recommended in surgeries that require quick recoveries. Remifentanil's terminal elimination half life in pediatric patients is $3.4-5.7$ minutes, which is very short and similar to the case of adults [13]. Therefore, remifentanil is considered to be effective in preventing the cardiovascular responses to short-term harmful stimulations such as ETI. There have been many reports on what the optimum dose of remifentanil is in adults who are undergoing ETI [14]. But in Korea, not many studies have been performed on the optimum dose of remifentanil in pediatric patients. Therefore, this research attempted to find the optimum dose that would minimize the cardiovascular changes due to ETI in pediatric patients.

\section{Materials and Methods}

This research first received the approval of the hospital's ethics committee. Then the guardians of the patients had the purpose and methodology of the study explained, and their informed consent was obtained.

Ninety ASA class I pediatric patients between the ages 4-15 and who were undergoing elective surgery under general anesthesia were chosen. Patients were excluded if they had a past history of cardiovascular disease, upper airway deformation, and if ETI had to be attempted twice or more because of difficult intubation. The patients were allocated to one of three groups in a randomized manner. Each group was respectively given remifentanil $1 \mathrm{ug} / \mathrm{kg}$ (Group R1; $\mathrm{N}=30$ ), 1.5 ug/kg (Group R1.5; N = 30), and 2 ug/kg (Group R2; N = 30).

When the patients arrived into the operating room, midazolam $0.05 \mathrm{mg} / \mathrm{kg}$ was intravenously administered. After the patients were stabilized on the operative table, a noninvasive blood pressure monitor (MP40, Philips, Germany), the ECG, and a pulse oximetry sensor were attached. Glycopyrrolate $5 \mathrm{ug} / \mathrm{kg}$ was intravenously administered as premedication. For anesthetic induction, thiopental sodium $4 \mathrm{mg} / \mathrm{kg}$ was intravenously administered. When the patient did not respond to oral commands and there was no eyelash reflex, remifentanil of the amount for the respective group was diluted in normal saline $5 \mathrm{ml}$ and this was administered by intravenous bolus injection over 10 seconds. This was quickly followed by the administration of rocuronium $0.6 \mathrm{mg} / \mathrm{kg}$. Ninety sec afterwards, ETI was performed using a curved laryngoscope (Macintosh, Heine, Germany).

Intubation was performed by a skilled anesthesiologist with 3 yrs of experience. Intubation was easy in most cases. After intubation, anesthesia was maintained by sevoflurane 2 vol\%, air $2.5 \mathrm{~L} / \mathrm{min}$ and, $\mathrm{O}_{2} 1.5 \mathrm{~L} / \mathrm{min}$. The ventilator settings were adjusted to maintain the end-expired carbon dioxide at 35$40 \mathrm{mmHg}$. After intubation, the blood pressure and heart rate were measured without fixing the tube or changing the body position of the patient for the patients whose blood pressure and heart rate would increase. The systolic blood pressure, mean blood pressure, and heart rate were measured before anesthetic induction (B), before intubation (BI), just after ETI (P 0), 1 minute after ETI (P 1), and 3 minutes after ETI (P 3). The rate of occurrence of coughing after remifentanil administration was also recorded.

All the data is presented as means \pm standard deviations. The results were processed on SPSS (version 17.0). The analysis of the gender of the 3 groups was performed using the chisquare test. The age, height, and weight were analyzed by oneway ANOVA. The comparative analyses of the blood pressure and heart rates among the groups were done using one-way ANOVA. A post-hoc analysis was performed using Duncan's test. The changes of the blood pressure and heart rate within the groups that were measured at different times were analyzed using repeated measures of ANOVA. P values $<0.05$ were considered to be statistically significant.

\section{Results}

There were no significant differences between the 3 groups for gender, age, height, or weight. Neither were there significant differences in the systolic blood pressure, mean blood pressure, 
and heart rate before anesthetic induction (Table 1).

The systolic blood pressure in all the 3 groups rose more than the baseline value (B) just after ETI $(\mathrm{P}<0.05)$ (Fig. 1). The systolic blood pressure just after ETI in Group R1 increased $30 \%$ (141.4 $\pm 17.9 \mathrm{mmHg})$ more than the baseline value, and it increased $19 \%(128.9 \pm 14.8 \mathrm{mmHg})$ more than the baseline value in Group R1.5, and 10\% (117.8 $\pm 13.0 \mathrm{mmHg})$ more than the baseline value in Group R2. In Group R2, the blood pressure just after ETI was significantly lower $(\mathrm{P}<0.05)$ compared to that of the other 2 groups. The systolic blood pressure eventually dropped in all 3 groups at $1 \mathrm{~min}$ post-ETI. At $3 \mathrm{~min}$ post ETI, the systolic blood pressure in Group R1 was $5 \%$ greater than the baseline value. In Groups R1.5 and R2, the systolic blood pressure was $5 \%$ and $10 \%$ lower than the baseline value, respectively. There was no significant difference between Group R1.5 and Group R2.

The mean blood pressure in all 3 groups rose just after

Table 1. Demographic Data

\begin{tabular}{lccc}
\hline & $\begin{array}{c}\text { Group R1 } \\
(\mathrm{n}=30)\end{array}$ & $\begin{array}{c}\text { Group R1.5 } \\
(\mathrm{n}=30)\end{array}$ & $\begin{array}{c}\text { Group R2 } \\
(\mathrm{n}=30)\end{array}$ \\
\hline Gender (M/F) & $14 / 16$ & $14 / 16$ & $18 / 12$ \\
Age (yr) & $7.6 \pm 3.2$ & $8.5 \pm 3.6$ & $7.9 \pm 2.9$ \\
Weight (kg) & $29.6 \pm 12.3$ & $32.3 \pm 12.3$ & $29.8 \pm 10.4$ \\
Height (cm) & $126.4 \pm 19.4$ & $132.8 \pm 21.9$ & $124.0 \pm 27.0$ \\
Baseline blood pressure & & & \\
SAP (mmHg) & $108.4 \pm 11.6$ & $107.9 \pm 11.7$ & $107.3 \pm 10.0$ \\
MAP (mmHg) & $73.9 \pm 11.7$ & $73.6 \pm 9.4$ & $71.9 \pm 8.4$ \\
Baseline HR (bpm) & $96.3 \pm 17.0$ & $93.8 \pm 14.2$ & $92.1 \pm 11.4$ \\
\hline
\end{tabular}

Value are means \pm SDs. R1: remifentanil $1.0 \mathrm{ug} / \mathrm{kg}$, R1.5: remifentanil $1.5 \mathrm{ug} / \mathrm{kg}$, R2: remifentanil $2 \mathrm{ug} / \mathrm{kg}$. SAP: systolic arterial pressure, MAP: mean arterial pressure, HR: heart rate. There were no significant differences among the three groups.

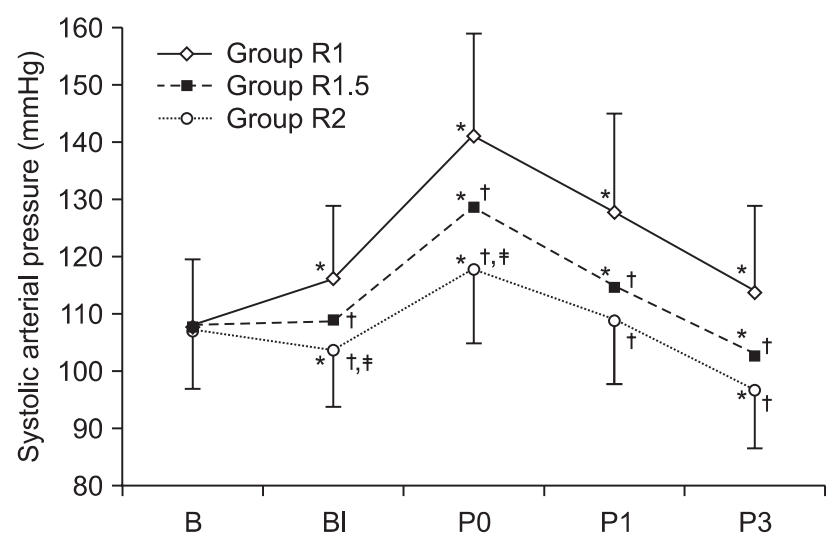

Fig. 1. Changes in the systolic arterial pressure (SAP). Group R1: remifentanil $1 \mathrm{ug} / \mathrm{kg}$, Group R1.5: remifentanil $1.5 \mathrm{ug} / \mathrm{kg}$, Group R2: remifentanil $2 \mathrm{ug} / \mathrm{kg}$, B: baseline, BI: before intubation, P0: just after intubation, P1 and, P3: 1 and, 3 minutes after intubation. $* \mathrm{P}<0.05$ compared with Baseline, ${ }^{\dagger} \mathrm{P}<0.05$ compared with Group R1, ${ }^{\ddagger} \mathrm{P}<$ 0.05 compared with Group R1.5. intubation ( $\mathrm{P}<0.05)$ (Fig. 2). The mean blood pressure just after ETI in Group R1 (106.5 $\pm 18.4 \mathrm{mmHg})$ rose $44 \%$ more than the baseline value, and it rose by $20 \%(86.5 \pm 12.4 \mathrm{mmHg})$, and $27 \%$ $(94.2 \pm 17.9 \mathrm{mmHg})$ more than the baseline value in Group R1 and R1.5, respectively $(\mathrm{P}<0.05)$. The mean blood pressure just after ETI in Group R2 and Group R1.5 was significantly lower than that in Group R1 $(\mathrm{P}<0.05)$. One minute post ETI, the mean blood pressure eventually dropped in all 3 groups. In Groups $\mathrm{R} 1$ and R1.5, the mean blood pressure was no different from the baseline rate, but in Group R2, it was $11 \%$ lower $(\mathrm{P}<0.05)$.

The heart rate in all three groups rose the most just after ETI compared to the baseline value and then it eventually decreased (Fig. 3). Just after ETI, Group R2 displayed a 22\% rise

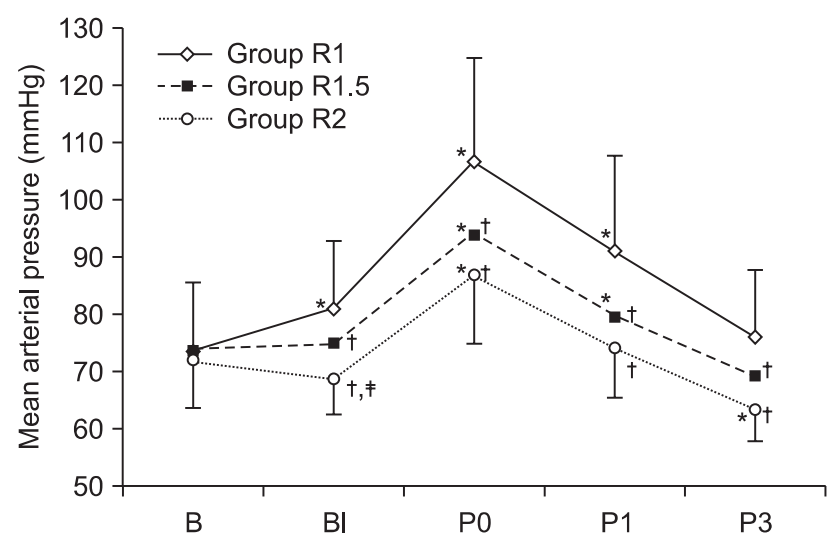

Fig. 2. Changes in the mean arterial pressure (MAP). Group R1: remifentanil $1 \mathrm{ug} / \mathrm{kg}$, Group R1.5: remifentanil $1.5 \mathrm{ug} / \mathrm{kg}$, Group R2: remifentanil $2 \mathrm{ug} / \mathrm{kg}$, B: baseline, BI: before intubation, P0: just after intubation, P1 and, P3: 1 and, 3 minutes after intubation. ${ }^{*} \mathrm{P}<0.05$ compared with Baseline, ${ }^{\dagger} \mathrm{P}<0.05$ compared with Group R1, ${ }^{\ddagger} \mathrm{P}<$ 0.05 compared with Group R1.5.

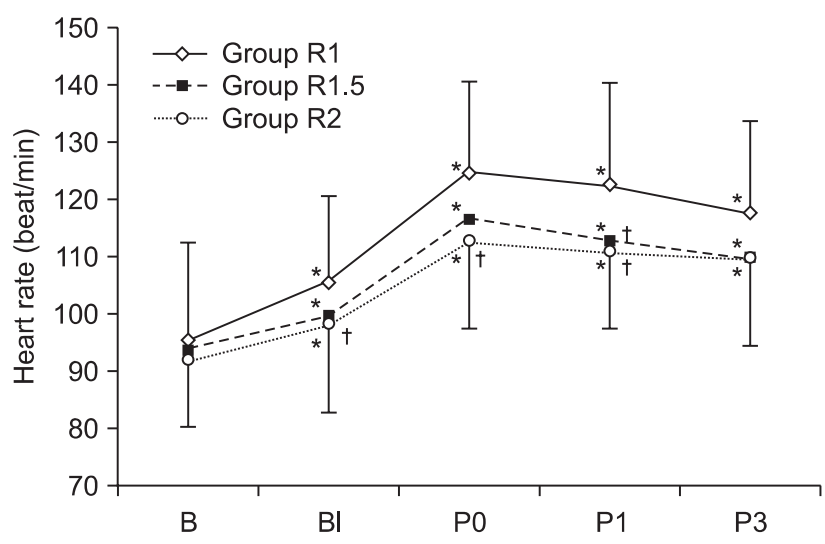

Fig. 3. Changes in heart rate (HR). Group R1: remifentanil $1 \mathrm{ug} / \mathrm{kg}$, Group R1.5: remifentanil $1.5 \mathrm{ug} / \mathrm{kg}$, Group R2: remifentanil $2 \mathrm{ug} /$ $\mathrm{kg}$, B: baseline, BI: before intubation, P0: just after intubation, P1 and, P3: 1 and, 3 minutes after intubation. ${ }^{*} \mathrm{P}<0.05$ compared with Baseline, ${ }^{\dagger} \mathrm{P}<0.05$ compared with Group R1. 
in the heart rate $(112.9 \pm 14.9 \mathrm{bpm})$, which was significantly less than the $30 \%$ rise of Group R1 $(125.1 \pm 16.1 \mathrm{bpm})(\mathrm{P}<0.05)$. But just after ETI, the heart rates of Group R1.5 (117.3 \pm 17.2 bpm) and Group R1 (125.1 \pm 16.1 bpm) were not significantly different. Three minutes after ETI, the heart rate was higher than the baseline value in all 3 groups, but there was no significant difference between them.

There was no significant difference in the rates of coughing after the bolus administration of remifentanil (Group R1: 53\%, Group R1.5: 60\%, Group R2: 56\%).

\section{Discussion}

The key finding of this study is that for general anesthesia using thiopental, remifentanil, and rocuronium for anesthetic induction in pediatric patients, remifentanil with the dose 2.0 $\mathrm{ug} / \mathrm{kg}$ best suppresses the cardiovascular responses to ETI.

Remifentanil's onset time is rapid and its duration of action is short. Therefore, it is effective regardless of the duration time of continuous infusion and, it is hydrolyzed at a set pace, so it is also the most preferred analgesic or anesthetic for diagnostic procedures and surgeries for pediatric patients [15]. Egan et al. [16] stated that when the use of strong analgesics over a short period is required, bolus IV infusion of remifentanil is safe and effective. So, we also chose the bolus administration method for remifentanil over the continuous infusion method. ETI was performed in this research $90 \mathrm{sec}$ after remifentanil injection because remifentanil's peak pharmacodynamic effect kicks in 1 to 2 minutes after the injection [17].

Xue et al. [10] stated that the optimum dose of remifentanil is 1 or $1.25 \mathrm{ug} / \mathrm{kg}$ for blunting the cardiovascular responses to ETI when anesthesia is induced in pediatric patients using propofol $2.5 \mathrm{mg} / \mathrm{kg}$ and vecuronium $0.1 \mathrm{mg} / \mathrm{kg}$. But in this study, the optimum dose of remifentanil was found to be 2 $\mathrm{ug} / \mathrm{kg}$. The difference compared to the findings of Xue et al. [10] is considered to be from our use of thiopental instead of propofol and the use of glycopyrrolate as premedication. Propofol $2.5 \mathrm{mg} / \mathrm{kg}$ that Xue et al. used is considered to be a much greater dose than the thiopental $4 \mathrm{mg} / \mathrm{kg}$ we used. Compared to thiopental, propofol causes less secretion of stress hormones due to anesthetic induction and ETI. It also suppresses the effect of catecholamine, which is secreted due to the stimulation of the intubation on the cardiovascular smooth muscle and so propofol does not greatly raise the blood pressure $[18,19]$. Thiopental $5-6 \mathrm{mg} / \mathrm{kg}$ is generally used for anesthetic induction. However, in our research, midazolam 0.05 $\mathrm{mg} / \mathrm{kg}$ was intravenously administered to calm the pediatric patients before anesthetic induction, and so we used thiopental $4 \mathrm{mg} / \mathrm{kg}$.

In the presented research, glycopyrrolate was also administered as premedication, which we assume caused the heart rate before intubation (BI) to increase in all 3 groups and the systolic blood pressure to rise in only Group R1. Xue et al. found that with remifentanil $1.25 \mathrm{ug} / \mathrm{kg}$, the systolic blood pressure and heart rate just after intubation rose $1 \%$ and $8 \%$, respectively. But our different findings of $10 \%$ and $22 \%$ increases in Group R2 are considered to be due to the presence of glycopyrrolate and propofol.

The fact that the blood pressure decreases after intubation should be considered when choosing the optimum amount of remifentanil for suppressing the post-intubation blood pressure elevation. In the present research, the blood pressure decreased slightly from the baseline value at 3 min post ETI in Group R1.5 and Group R2 (5\% and 10\% respectively). But there was no significant difference between the two groups. So remifentanil at the dose $2.0 \mathrm{ug} / \mathrm{kg}$ is considered the appropriate dose for greater suppression of the elevated blood pressure elevation just after ETI. Also in Xue et al.'s findings, remifentanil $1 \mathrm{ug} /$ $\mathrm{kg}$ and $1.25 \mathrm{ug} / \mathrm{kg}$ reduced the systolic blood pressure around $15 \%$ below the baseline value at 5 min after intubation. But this is considered to be from the use of propofol because the control group, where remifentanil was not used, showed no difference in the drop in blood pressure. Cha et al. [20] stated that remifentanil $0.5 \mathrm{ug} / \mathrm{kg}$ is appropriate to suppress the cardiovascular responses to ETI in adults when anesthesia is induced by propofol $2 \mathrm{mg} / \mathrm{kg}$ or rocuronium $1 \mathrm{mg} / \mathrm{kg}$. Lee et al. [21] also reported that remifentanil $1 \mathrm{ug} / \mathrm{kg}$ is appropriate when anesthesia is induced by sevoflurane 2 vol\% and $\mathrm{N}_{2} \mathrm{O}$ $50 \%$ in adults. McAtamney et al. [22] reported that remifentanil $1.0 \mathrm{ug} / \mathrm{kg}$ is the optimum dose when anesthesia is induced by thiopental $5-7 \mathrm{mg} / \mathrm{kg}$ and rocuronium $0.75 \mathrm{mg} / \mathrm{kg}$ in adults. In summary, the optimum dose of remifentanil has been reported to be $0.5-1.0 \mathrm{ug} / \mathrm{kg}$, but for children, this study demonstrated that the optimum dose is $2 \mathrm{ug} / \mathrm{kg}$, which is a higher dose than that for adults. Although it is difficult to make accurate comparisons between anesthetic inducers and their dose, it is thought that the dose for children does not necessarily have to be smaller than that for adults. Ross et al. [13] stated that remifentanil's volume of distribution is pharmacokinetically greater for children and, its clearance rate is faster, but there was no difference seen in the elimination rate.

Mark et al. [23] stated that in children where muscle relaxants have not been used and propofol $4 \mathrm{mg} / \mathrm{kg}$ was used for anesthetic induction, remifentanil's optimum dose is $3.0 \mathrm{ug} /$ $\mathrm{kg}$. Blair et al. [6] stated that when using propofol $3 \mathrm{mg} / \mathrm{kg}$ for anesthetic induction in the absence of muscle relaxants, remifentanil 2-3 ug/ $\mathrm{kg}$ will decrease the blood concentration of catecholamine, it will not raise the blood pressure and heart rate due to ETI, and it will bring about hemodynamic stabilization. Klemola and Hiller [24] stated that in the absence 
of muscle relaxants, propofol $3.5 \mathrm{mg} / \mathrm{kg}$ and remifentanil $4 \mathrm{ug} /$ $\mathrm{kg}$ provide the best conditions for intubation. For pediatric anesthesia, when intubation is performed without muscle relaxants, a greater dose of remifentanil has generally been used.

In this present study, rocuronium $0.6 \mathrm{mg} / \mathrm{kg}$ was administered for intubation. Most of the surgeries were short like a tonsillectomy, so a greater dose was not needed. Ninety seconds after administering rocuronium, ETI were performed uneventfully. Eikermann et al. [25] stated that ETI was easy 2 minutes after administering rocuronium $0.6 \mathrm{mg} / \mathrm{kg}$ in pediatric patients where inhalational anesthesia with sevoflurane $8 \%$ and nitrous oxide $60 \%$ was used.

Coughing, a side effect of the use of opioids, was found in Groups R1, R1.5, and R2 with the respective frequency of $53 \%, 60 \%$, and $56 \%$. There was no statistically significant difference found among the 3 groups. This may be because only the presence/absence of coughing was recorded and the frequency was not. There were no other findings such as bradycardia. Coughing that occurs during anesthetic induction can elevate the intracranial pressure, intraocular pressure, and intra-abdominal pressure; in the case of severe coughing, immediate intervention is required [26]. Xue et al. [10] reported that they did not encounter opioid-related side effect, such as bradycardia, coughing or chest rigidity. In our study, remifentanil was intravenously administered over 10 seconds. But Xue et al. administered it over 30 seconds and there were no side effects, which may be due to the small dose ( 1 or 1.25 ug/kg). Lin et al. [27] stated that the incidence of coughing from fentanyl can be reduced by its slow administration. More studies are needed on the relationship of coughing to the dose of remifentanil, the method of administration and the infusion speed.

Whether the appropriate dose for remifentanil is lower when the thiopental is increased from $4 \mathrm{mg} / \mathrm{kg}$ to $5 \mathrm{mg} / \mathrm{kg}$ or when propofol is used instead needs to be addressed in another study.

We know that the greater the amount of bolus infusion of remifentanil, the greater the increased blood pressure just after intubation is suppressed. However, when choosing the appropriate dose, one must also consider that the blood pressure drops to a greater degree after 3 minute post ETI.

In conclusion, the bolus injection of remifentanil $2 \mathrm{ug} / \mathrm{kg}$ was found to be effective to minimize the cardiovascular responses when anesthesia is induced in pediatric patients using thiopental and rocuronium.

\section{References}

1. Shribman AJ, Smith G, Achola KJ. Cardiovascular and catechola- mine responses to laryngoscopy with and without tracheal intubation. Br J Anaesth 1987; 59: 295-9.

2. Derbyshire DR, Chmielewski A, Fell D, Vater M, Achola K, Smith G. Plasma catecholamine responses to tracheal intubation. Br J Anaesth 1983; 55: 855-60.

3. Edwards ND, Alford AM, Dobson PM, Peacock JE, Reilly CS. Myocardial ischaemia during tracheal intubation and extubation. Br J Anaesth 1994; 73: 537-9.

4. Fox EJ, Sklar GS, Hill CH, Villanueva R, King BD. Complications related to the pressor response to endotracheal intubation. Anesthesiology 1977; 47: 524-5.

5. Stone JG, Foëx P, Sear JW, Johnson LL, Khambatta HJ, Triner L. Risk of myocardial ischaemia during anaesthesia in treated and untreated hypertensive patients. Br J Anaesth 1988; 61: 675-9.

6. Blair JM, Hill DA, Wilson CM, Fee JP. Assessment of tracheal intubation in children after induction with propofol and different doses of remifentanil. Anaesthesia 2004; 59: 27-33.

7. Laussen PC, Wessel DL. Anesthesia for congenital heart disease. In: Pediatric Anesthesia. 4th ed. Edited by Gregory GA: Philadelphia, Churchill Livingstone. 2002, p 490.

8. Bissonnette B, Dalens B. Pediatric Anesthesia: Principles \& practice. New York, McGraw-Hill Company. 2002, p 786, 1131.

9. Gupta A, Kaur R, Malhotra R, Kale S. Comparative evaluation of different doses of propofol preceded by fentanyl on intubating conditions and pressor response during tracheal intubation without muscle relaxants. Paediatr Anaesth 2006; 16: 399-405.

10. Xue FS, Xu YC, Liu Y, Yang QY, Liao X, Liu KP, et al. Different small-dose remifentanil blunting the cardiovascular response to laryngoscopy and intubation in children: a randomized doubleblind comparison. Eur J Anaesthesiol 2008; 25: 106-12.

11. Prakanrattana U, Suksompong S. Comparison of sufentanil and fentanyl for surgical repair of congenital cardiac defects. J Med Assoc Thai 2002; 85: S807-14.

12. Beers R, Camporesi E. Remifentanil update: clinical science and utility. CNS Drugs 2004; 18: 1085-104.

13. Ross AK, Davis PJ, Dear Gd GL, Ginsberg B, McGowan FX, Stiller $\mathrm{RD}$, et al. Pharmacokinetics of remifentanil in anesthetized pediatric patients undergoing elective surgery or diagnostic procedures. Anesth Analg 2001; 93: 1393-401.

14. Byun SJ, Hwang SH, Kim JH, Ban JS, Min BW. What is the optimal dosage of remifentanil for minimizing the hemodynamic change to tracheal intubation during induction with propofol targetcontrolled infusion? Korean J Anesthesiol 2006; 50: 140-5.

15. Davis PJ, Cladis FP. The use of ultra-short-acting opioids in paediatric anaesthesia: the role of remifentanil. Clin Pharmacokinet 2005; 44: 787-96.

16. Egan TD, Kern SE, Muir KT, White J. Remifentanil by bolus injection: a safety, pharmacokinetic, pharmacodynamic, and age effect investigation in human volunteers. Br J Anaesth 2004; 92: 335-43.

17. Glass PS, Gan TJ, Howell S. A review of the pharmacokinetics and pharmacodynamics of remifentanil. Anesth Analg 1999; 89: S7-14.

18. Choi WJ, Jeon WJ, Shim JH, Cho SY, Yeom JH, Shim WJ, et al. The influence of clonidine premedication on the A-line ${ }^{\mathrm{TM}}$ ARX index and hemodynamics during anesthesia induction with propofol. Korean J Anesthesiol 2003; 45: 13-21.

19. Kwon BY, Lee JS, Kim SH. A comparison of the induction charac- 
teristics of propofol and thiopental on the hypertensive patients. Korean J Anesthesiol 1994; 27: 1734-9.

20. Cha JW, Kwak SH, Kim SJ, Choi JI, Kim CM, Jeong ST, et al. Optimal dose of remifentanil to blunt hemodynamic response to laryngoscopy and endotracheal intubation during induction of anesthesia with propofol. Korean J Anesthesiol 2006; 51: 292-6.

21. Lee JR, Jung CW, Lee JH, Choi IY, Seo KS, Kim HK, et al. Optimal dose of remifentanil to suppress cardiovascular responses to laryngoscopic endotracheal intubation. Korean J Anesthesiol 2005; 49: 780-5.

22. McAtamney D, O'Hare R, Hughes D, Carabine U, Mirakhur R. Evaluation of remifentanil for control of haemodynamic response to tracheal intubation. Anaesthesia 1998; 53: 1223-7.

23. Crawford MW, Hayes J, Tan JM. Dose-response of remifentanil for tracheal intubation in infants. Anesth Analg 2005; 100: 1599-604.

24. Klemola UM, Hiller A. Tracheal intubation after induction of anesthesia in children with propofol-remifentnil or propofolrocuronium. Can J Anaesth 2000; 47: 854-9.

25. Eikermann M, Hunkemöller I, Peine L, Armbruster W, Stegen B, Hüsing J, et al. Optimal rocuronium dose for intubation during inhalation induction with sevoflurane in children. Br J Anaesth 2002; 89: 277-81.

26. Tweed WA, Dakin D. Explosive coughing after bolus fentanyl injection. Anesth Analg 2001; 92: 1442-3.

27. Lin JA, Yeh CC, Lee MS, Wu CT, Lin SL, Wong CS. Prolonged injection time and light smoking decrease the incidence of fentanylinduced cough. Anesth Analg 2005; 101: 670-4. 